\title{
Optic Nerve Sheath Diameter in retrobulbar ultrasound as a surrogate measure for intracranial pressure before and after non-invasive strategies.
}

aldo saad diab ( $\sim$ aldosaad23@gmail.com )

Centro Medico Docente La Trinidad

Benailim Martínez

Hospital Dr Miguel Perez Carreno

Albana Gámez

Hospital Dr Miguel Perez Carreno

Yvan Bucott

Hospital Dr Miguel Perez Carreno

Research article

Keywords: intracranial hypertension, intracranial pressure, optic nerve sheath diameter, osmotherapy, Reverse Trendelenburg position

Posted Date: November 2nd, 2019

DOI: https://doi.org/10.21203/rs.2.16537/v1

License: (9) This work is licensed under a Creative Commons Attribution 4.0 International License. Read Full License 


\section{Abstract}

Background : Raised intracranial pressure is a complication that leads to adverse outcomes. In the critically ill, invasive measurement by an intraventricular catheter is the gold standard; its use in nonspecialized centers is limited, besides neuroimaging by computed tomography or magnetic resonance imaging scans entail transfer of a critically ill patient out of the ICU. Dilatation of the optic nerve sheath has been shown to be a much earlier manifestation of ICP rise. The optic nerve sheath diameter (ONSD) is fairly easy to visualize by ultrasonography by insonation across the orbit

Methods: 90 patients, divided into three groups. Group M received mannitol $20 \% 0.5 \mathrm{gr} \mathrm{kg} \mathrm{-1}$, Group H received $\mathrm{NaCl} 7.5 \% 1.5 \mathrm{ml} \mathrm{kg} \mathrm{-1}$ and Group P patients were positioned on reverse Trendelenburg position 30 degrees. ONSD was measured $3 \mathrm{~mm}$ behind the optic disc. The measurements T1 before and T2 after the strategies according to group $30 \mathrm{~min}, \mathrm{~T} 3$ at $60 \mathrm{~min}$, and T4 at $90 \mathrm{~min}$

Results: Similar trend between invasive monitoring and ONSD measurement was observed. Invasive measurement the intracranial pressure was 40.2 at $\mathrm{T} 1$, there was a sustained and significant decrease in the three groups at 30,60 and 90 minutes. ONSD measured at baseline, average was $7.0 \mathrm{~mm}$ in group $\mathrm{M}$, 7.1 in group $H$ and 6.7 in group $P$, and subsequently it was significantly reduced at $30,60(p=0.002)$ and 90 minutes $(p=0.003)$.

Conclusion: ONSD in retrobulbar ultrasound is a reliable method to detect intracranial pressure variations before and after non-invasive strategies to reduce it acutely Keywords: intracranial hypertension, intracranial pressure, optic nerve sheath diameter, osmotherapy, Reverse Trendelenburg position. Trial registration: Clinical Trials; NCT03634176 ; registered August 16, 2018; https://clinicaltrials.gov/ct2/show/NCT03634176.

\section{Background}

Patients with brain injury usually present in emergency services; mainly due to traumatic or vascular causes, and less frequently due to the presence of tumors, hydrocephalus and central nervous system infections. Regardless of the cause, the increase in volume within the skull, combined with the loss of compensatory mechanisms, consequently produce an increase in intracranial pressure (ICP). ${ }^{1,2}$

There are different tools to measure ICP that can be invasive or non-invasive, each of which present different peculiarities and complications. ${ }^{3}$ However, the ideal technique to measure the ICP would be with the following characteristics:

- Non-invasive and can be performed at the patient's bedside.

- High sensitivity and specificity, without the risk of complications. ${ }^{4}$ 
- Served by any member of the health staff in charge of the patient with a low learning curve, easily accessible in all health institutions and at low cost $^{-5,6}$

Currently the assessment of ICP is a challenging problem as it is rarely achieved without neuroimaging or invasive monitoring.

Cranial computed tomography (CT) is the study of choice to identify the presence and extent of damage in the intracranial cavity, provides essential information with implication in therapeutic measures for surgical intervention or ICP monitoring and also provides objective information on neurological prognosis, although cranial CT is available in most of the emergency services this type of studies may not show findings corresponding to elevation of the ICP. The disadvantages of using CT include lack of real-time measurement and inability to obtain measurement reports, both in terms of logistics, radiation exposure and costs. ${ }^{7}$

While the measurement of ICP through the intraventricular catheter connected to an external transducer is considered the gold standard, its use in non-specialized centers is limited due to its highly invasive nature and multiple infectious disorders, hemorrhages, catheter obstruction, difficulty in placement, poor positioning, in addition to high costs and the need for personnel with special training for its use. ${ }^{8,9}$ Limiting not only the diagnosis but also the evolution after the application of any treatment to reduce the ICP once diagnosed, being one of the cornerstones in the resolution of this neurological complication, thus compromising the cerebral perfusion pressure (CPP) and consequences such as ischemia cerebral and cerebrovascular disorders. ${ }^{10,11}$

A non-invasive and reliable monitoring modality has been developed, which is why the current points of controversy regarding the monitoring of intracranial pressure are increasing in the selection of patients, in the search for more reliable monitoring methods, less invasive and reproducible that allow not only to diagnose but also to evaluate the real time or short term of the clinical evolution before and after the strategies already known to reduce ICP and improve CPP, maximizing recovery possibilities. ${ }^{12}$

The measurement of the optic nerve sheath diameter (ONSD) by ultrasonography has been applied in clinical practice. ${ }^{1}$ Ontogenetically the optic nerve is part of the central nervous system, it is surrounded by cerebrospinal subarachnoid fluid (CSF) and dura mater (optic nerve sheath), therefore the ONSD changes after pressure variations of CSF. ${ }^{13}, 14$. Anatomically the sheath of the optic nerve contains the nerve and the nervous perioptical sheath, which is continuous with the dura of the brain. As cerebrospinal fluid is present in the subarachnoid space of the optic nerve sheath, increases in ICP result in increases in ONSD, especially $3 \mathrm{~mm}$ behind the margin of the optic disc; this area, because it contains thin and irregular fibers, is more sensitive to increases in ICP. ${ }^{15}$ There are several investigations that have shown that there is an adequate correlation between the ONSD and the measurement of intracranial pressure. An ONSD value of $5 \mathrm{~mm}$ was considered the cutoff value suggestive of an increased ICP $(>20 \mathrm{mmHg}){ }^{16,17}$ However, despite the practicality and innocuousness of this technique for monitoring ICP as well as the ease of performing it at the patient's bedside early, there is not much evidence on how ONSD is affected 
by a treatment directed against elevation of the patient ICP and if its estimation through ultrasonography can replace the measurement by invasive monitoring. ${ }^{18}$

\section{Methods}

This study was conducted between September 2018 and May 2019 in the anesthesiology department of Hospital Dr. Miguel Perez Carreño. The study protocol was approved by the Institutional Review Board, and all participants provided written informed consent. This trial has been registered at ClinicalTrials.gov NCT03634176

\section{Patient selection criteria}

Adult patients with traumatic or non-traumatic elevated ICP (defined as greater than $20 \mathrm{~mm} \mathrm{Hg}$ for at least $10 \mathrm{~min}$ ), hospitalized in intensive care unit (ICU) with ICP, continuous measurement through an intraventricular catheter, respiratory rate between 10-18 $\mathrm{min}^{-1}$ to maintain end tidal carbon dioxide partial pressure (ETCO2) between 35 and $40 \mathrm{mmHg}$, Peak airway pressure $<35 \mathrm{cmH}_{2} \mathrm{O}$ and Positive endexpiratory pressure $<5 \mathrm{cmH}_{2} \mathrm{O}$

Patient exclusion criteria

Patients who had undergone cranial decompression surgery and patients with ocular pathology or who had previously undergone eye surgery

All the included patients were randomized into three groups (30 for each group) by assigning a sealed envelope. In the ICU area, patients belonging to Group M received mannitol $20 \% 0.5 \mathrm{gr} \mathrm{kg}^{-1}$, Group H received $\mathrm{NaCl} 7.5 \% 1.5 \mathrm{ml} \mathrm{kg}^{-1}$ and Group P patients were positioned on reverse Trendelenburg position 30 degrees higher than the feet.

Among these 90 patients were recorded the measurement of the vertical and horizontal diameters of the optic nerves of both eyes measured by ultrasonography

The ONSD was measured by two experienced anesthesiologists who had previously measured ONSDs ultrasonographically in more than 100 patients. Initially the patients were placed in a neutral position with their eyelids fully closed and safely taped. The eyelids were covered with thick gel, and a 7.5MHz linear probe (M7 Premium Mindray Ultrasound system) was placed over the eyelids. The ONSD in each eye was measured vertically and horizontally $3 \mathrm{~mm}$ behind the optic disc, with the two values averaged. No pressure was applied to the orbit. At each time point, measurements were taken within $5 \mathrm{~min}$. The measurements were made before (T1) and after some of the strategies according to group $30 \mathrm{~min}$ (T2), $60 \mathrm{~min}$ (T3), and $90 \mathrm{~min}$ (T4). In addition, hemodynamic and respiratory variables were monitored during the study.

The patient and the expert who analyzed the data were blind to the strategies used. 
Statistical analysis

A database was carried out in the statistical program SPSS 19.0; the variables were analyzed through descriptive statistics of mean, median standard deviation with a $95 \%$ confidence interval, frequencies and percentages as the case may be. ANOVA statistical test was applied to compare invasive intracranial pressure and ONSD in groups $\mathrm{M}, \mathrm{H}$ and $\mathrm{P}$ at baseline, at 30,60 and 90 minutes. Based on the baseline value, Pearson's R correlation was applied and the ICP and ONSD groups were compared, a value of $p$ $<0.05$ was considered statistically significant and highly significant when $p<0.01$. The format of the tables and the figure were made in the Microsoft Office Excel program.

\section{Results}

Of the patients who met the selection criteria, the median age was $46 \pm 14.9$ years, $42.2 \%$ were female and $57.8 \%$ male, the most frequent admission diagnoses were brain tumors $38.9 \%$, followed by Traumatic brain injury $31.1 \%$ and finally subarachnoid hemorrhage $30.0 \%$ (Table 1 ).

On average the measurement of intracranial pressure was 40.2 at baseline, then a sustained and significant decrease $(p<0.001)$ was observed in the three groups at 30,60 and 90 minutes, being at 90 minutes a Normal average intracranial pressure value in both groups $\mathrm{M}$ (mannitol) and $\mathrm{H}$ (hypertonic) not so for Group P (Table 2).

A similar trend was observed when measuring ONSD that, at baseline, the average was $7.0 \mathrm{~mm}$ in group $M, 7.1$ in group $H$, and 6.7 in group $P$, and subsequently significantly reduced at $30(p<0.001), 60(p=$ 0.002 ) and 90 minutes $(p=0.003)$, the latter being lower in group $H$ (mean $=5.9 \pm 0,7 \mathrm{~mm})$, followed by the group $M($ mean $=6.3 \pm 0.5 \mathrm{~mm})($ Table 3$)$.

Figure 1 shows a statistically significant inverse correlation $(p<0.05)$ of the decrease in intracranial pressure being more marked with the invasive method (Pearson's $r$ correlation from 1 to 0.22 , at 90 minutes), being less marked and equally significant in the ONSD group (Pearson's $r$ correlation of 1 at baseline to 0.64 at 90 minutes).

\section{Discussion}

In patients with brain injury, the increase in intracranial pressure (ICP) is a devastating consequence, resulting in a decrease in cerebral perfusion pressure, leading to ischemia, brain swelling and even death. 19

Therefore, it is important to maintain an adequate and accurate measurement and monitoring of intracranial pressure, with not only for diagnostic purposes but also as therapeutic guide and prognosis. 19 
The gold standard method to measurement ICP is through an intraventricular catheter, but is important to emphasize that it can be complicated to perform, since it requires trained personal also it can be difficult for placement, it might not be available in all health centers and it can have a high cost in addition to generate multiple complications. 8,9

Previous studies have shown that the measurement of the optic nerve sheath diameter (ONSD) through ultrasound can be correlated with the increase of intracranial pressure, this is a less invasive method, simple to perform, more affordable since the equipment is widely available in emergency rooms and hospitals in general, also generating fewer complications. ${ }^{20}$

Prior findings had established a cut-off point of $5 \mathrm{~mm}$ or greater in ONSD measurement suggesting an ICP of $20 \mathrm{mmHg}$ or above ${ }^{16,17}$. Our results correspond with this, showing that with an ICP increased, measured through an Interventricular catheter (Table 2) the values of the ONSD are superior to $5 \mathrm{~mm}$ (Table 3). Thus, our findings agree with previous studies ${ }^{20,21}$ in the usefulness of ultrasonography and its correlation invasive ICP measure.

However, there are few studies that besides making a diagnosis approach of an increased ICP through ultrasonography show that after application of therapeutic measures to reduce it, the OSND will change too; thus making a direct relationship between invasive and non-invasive measurements is not quite accurate. ${ }^{20}$

A previous study published by Launey and colleagues in $2014^{22}$ that included invasive measurements of ICP through an intraventricular catheter and the ONSD before and after using $20 \%$ mannitol, found that both measures decreased significantly after using such therapy. Also Wang and co-workers in $2018^{23}$ in his study where they measured the ICP through lumbar puncture and also the ONSD was recorded before and after using etiological and osmotic treatment, with a follow up for 1 month, shows that ICP changes in an invasive an non-invasive way were highly related.

Our results agree with these findings, showing that only after 30 minutes of therapeutic measures in the 3 study groups there was a decrease in the ONSD between 0,4 and $1 \mathrm{~mm}$. With higher changes in the $\mathrm{H}$ group (baseline: $7.1 \mathrm{~mm}$ SD 0.86 - 30min: $6.0 \mathrm{~mm}$ SD $0.7 \mathrm{p}<0.001$ ) and the lowest in the P group (baseline: $6.7 \mathrm{~mm}$ SD 0.6 - 30min: $6.6 \mathrm{~mm}$ SD $0.6 \mathrm{p}<0.001$ ) (table 3).

However, compared with the changes obtained through an invasive measurement after 30 min of treatment, with results ranged between from $4.7 \mathrm{mmHg}$ to $19.7 \mathrm{mmHg}$ (table 2), also being the higher ones in the H group (baseline: $40.6 \mathrm{mmHg}$ SD 9.2-30min: $20.9 \mathrm{mmHg}$ SD $4.3 \mathrm{p}<0.001$ ) and the lowest in P group (baseline: $39.8 \mathrm{mmHg}$ SD 8 - 30min: $35.9 \mathrm{mmHg}$ SD $7.8 \mathrm{p}<0.001$ ) the ONSD changes were minor. This situation tends to continue in the 60 minutes follow up, where the ICP variations were more notorious and greater in the invasive measurements than in the non-invasive. (Figure 1)

Moreover, by the following 90 min we obtained almost normal ICP values invasively for $\mathrm{M}$ and $\mathrm{H}$ group (M group: 18.7 mmHg SD 2.8 - H group: 18.6 mmHg SD 3, 1 p <0.001) (table 2). On the other hand, these 
trends are not seeing in the OSND measurement where the values are still in upper ranges (M group: 6.3 mm SD 0.5 - H group: 5.9 mm SD 0.6 p 0.003) (Table 3- Figure 1). These findings oppose to the ones of Wang and colleagues. ${ }^{23}$ where after the follow-up they return to the baseline values, but they do not mention the exact time needed to reach it.

As previous studies demonstrated, ontogenetically the optic nerve is part of the central nervous system, 13,14 morphologically it is noted that the trabeculae and partitions within the subarachnoid space of the optic nerve provides a strong anatomical evidence of the hydrodynamics between and within the different segments of cerebrospinal fluid. ${ }^{24}$

However, despite of ONSD measurements is clearly a reliable method to detect increases in ICP at bedside that correlates well with invasive measurements $(20,22,25,26)$, there is a lack data that demonstrate the direct variations relationships after therapeutic measures between invasive measurements and ultrasonography, either by small sample, poorly standardized or measurements in unspecified time intervals. ${ }^{22-23}$

Our findings agree with the fact that there are certainly changes in the ONSD after osmotic therapies as previous ones, ${ }^{22-23}$ still the ONSD does not return normal values despite is obtained in the invasive way (table 3 - figure 1), showing that perhaps is not a highly reliable method to guide therapeutics and prognosis.

Thus, our study has some limitations since we have a small sample, we made a short follow-up, we only were able to evaluated for $90 \mathrm{~min}$ and not for 1 month or until we obtain normal values. So we suggest further studies that look forward to determinate this time interval, as well contrast with tomographic changes.

\section{Conclusions}

The Optic Nerve Sheath Diameter in retrobulbar ultrasound is a reliable method to detect ICP variations before and after non-invasive strategies to reduce it acutely, as our results show, it can be expected variations up to $1 \mathrm{~mm}$ in diameter after only $30 \mathrm{~min}$ of treatment. Yet, these changes are not proportional in terms of invasive measurements, where it could to yield values close to the normal range and still have an altered ONSD, noting that longer follow-up intervals are required to see normal values in the OSND.

For those reason we recommend that OSND changes will not be interpreting in isolation to guide the patient treatment, however it can aid as a bedside approach to know if the management is working but does not replace invasive methods and a comprehensive clinical analysis.

\section{Declarations}

\section{Abbreviations}


ANOVA: Analysis of Variance; BT: Brain Tumor; CPP: Cerebral Perfusion Pressure; CSF: Cerebrospinal Subarachnoid Fluid; CT: Computed Tomography; ETCO2: End Tidal carbon dioxide; ICP: Intracranial pressure; ICU: Intensive Care Unit; ONSD: Optic Nerve Sheath Diameter; SAH Subarachnoid Hemorrhage; SD: Standard Deviation; TBI: Traumatic Brain Injury.

Ethics approval and consent to participate: The study is approved by the Research Ethics Committee and the Institutional Review Board of the "Dr. Miguel Pérez Carreño"Hospital. A written informed consent was obtained from all patients.

Consent for publication: Not applicable.

Availability of data and materials: The data that support the findings of this study are available from "Dr. Miguel Pérez Carreño"Hospital; however, they are not publicly available. Data are however available from the authors upon reasonable request after permission of the institution.

\section{Competing interests: The authors declare that they have no conflicts of interests.}

\section{Funding: No funding, the "Dr. Miguel Pérez Carreño"Hospital resources were used.}

Authors' contributions: Study design/planning: ASD, YB. Study conduct: BM, ASD, YB. Data analysis: BM, ASD. Writing paper: AG, ASD, BM. Revising paper: ASD, BM, AB, YB. All authors read approved the final version of the manuscript.

\section{Acknowledgments: We thank our colleagues from "Dr. Miguel Pérez Carreño"Hospital who provided insight and expertise that greatly assisted the research.}

\section{References}

1. Sadik Girisgin A, Kalkan E, Kocak S, Cander B, Gul M, Semiz M. The role of optic nerve ultrasonography in the diagnosis of elevated intracranial pressure. Emerg Med J 2007; 24:251-254.

2. Newman WD, Hollman AS, Dutton GN, Carachi R. Measurement of optic nerve sheath diameter by ultrasound: a means of detecting acute raised intracranial pressure in hydrocephalus. Br J Ophthalmol 2002 Oct; 86(10):1109-13. 
3. Zhang X, Medow JE, Iskandar BJ, Wang F, Shokoueinejad M, Koueik J, et al.

Invasive and noninvasive means of measuring intracranial pressure: a review. Physiol Meas 2017 Jul 24; 38(8):R143-R182.

4. Das S, Shetty S, Sen K. A Novel Triage Tool: Optic Nerve Sheath Diameter in Traumatic Brain Injury and its Correlation to Rotterdam Computed Tomography (CT) Scoring. Pol J Radiol 2017; 82:240-243.

5. Bellal J, Muhammad K, Peter R. Non-invasive diagnosis and treatment strategies for traumatic brain injury: an update. J Neurosci Res 2017; 1-12.

6. Khan MN, Shallwani H, Khan MU, Shamim MS. Noninvasive monitoring intracranial pressure - A review of available modalities. Surg Neurol Int 2017; 8:1-11 7. García JR, Zapata R, Alonzo F, Rodriguez S, Medina M, Torres JL. Monitoring of intracranial pressure in severe craniocephalic trauma: clinical experience. Rev Chil Pediatr 2016; 87(5)387-394.

8. Raboel PH, Bartek J, Andresen M, Bellander BM, Romner B. Intracranial Pressure monitoring : invasive versus non-invasive methods, a review. Crit Care Res Pract 2012; 114.

9. Ozturk T, Demir H, Yorulmaz R, Ozdemir S, Isat G, Onur O. Assessment of intrainterobserver reliability of the sonographic optic nerve sheath diameter measure ment. Kaohsiung J Med 2015; 31(8):432-436.

10. Smith M. Monitoring intracranial pressure in traumatic brain injury. Anesthesia and Analgesia 2008; 106(1):240-248.

11. Akopian G, Gaspard DJ, Alexander M. Outcomes of blunt head trauma without intracranial pressure monitoring. American Surgeon 2007; 73(5):447-450.

12. Sahuquillo J, Poca MA, Pedraza S, Munar X. Updates on the pathophysiology and monitoring of severe head injuries. Neurosurgery 1997; 8:260-283.

13. Blaivas M, Theodoro D, Sierzenski PR. Elevated intracranial pressure detected by bedside emergency ultrasonography of the optic nerve sheath. Acad Emerg Med 2003 Apr; $10(4): 376-81$.

14. Jang T, Aubin C. The use of serial ocular ultrasonography in the care of patients with head injury. Ann Emerg Med 2005 Mar; 45(3):336-7. 
15. Gangemi M, Cennamo G, Maiuri F. et al. Echographic measurement of the optic nerve in patients with intracranial hypertension. Neurochirugica 1987; 30:53-5.

16. Tayal VS, Neulander M, Norton HJ, Foster T, Saunders T, Blaivas M. Emergency department sonographic measurement of optic nerve sheath diameter to detect findings of increased intracranial pressure in adult head injury patients. Ann Emerg Med 2007; 49(4):508-14.

17. Chen H, Ding GS, Zhao YC, Yu RG, Zhou JX. Ultrasound measurement of optic nerve diameter and optic nerve sheath diameter in healthy Chinese adults. BMC Neurol 2015; 15:106.

18. Wang L, Feng L, Yao Y, Deng F, Wang Y, Feng J, et al. Ultrasonographic Evaluation of Optic Nerve Sheath Diameter among Healthy Chinese Adults. Ultrasound Med Biol 2016; $42(3): 683-8$.

19. Smith E, Hanjani S. Evaluation and management of elevated intracranial pressure in adults. In Aminoff M, ed. UpToDate. Waltham, MASS.: UpToDate Inc, 2019. https://www.uptodate.com/contents/evaluation-and-management-of-elevated-intracranialpressure-in-adults?source=history_widget. (Accessed on September, 2019)

20. Dubourg J, Javouhey E, Geeraerts T, Messerer M, Kassai B. Ultrasonography of optic nerve sheath diameter for detection of raised intracranial pressure: a systematic review and meta-analysis. Intensive Care Med 2011 Jul; 37(7):1059-68.

21. Geeraerts T, Launey Y, Martin L, Pottecher J, Vigué B, Duranteau J, et al. Ultrasonography of the optic nerve sheath may be useful for detecting raised intracranial pressure after severe brain injury. Intensive Care Med 2007 Oct; 33(10):1704-11.

22. Launey Y, Nesseler N, Le Maguet P, Mallédant Y, Seguin P. Effect of osmotherapy on optic nerve sheath diameter in patients with increased intracranial pressure. J Neurotrauma 2014 May; 31(10): 984-8.

23. Wang L, Chen L, Chen Y, Bao L, Zheng N, Wang Y et al. Ultrasonography assesments of optic nerve sheath diameter as a noninvasive and dynamic method of detecting changes in intracranial pressure. JAMA Ophthalmol 2018 Mar 1; 136(3):250-256. 24. Killer H, Laeng H, Flammer J, Groscurth P. Architecture of arachnoid trabeculae, pillars, and septa in the subarachnoid space of the human optic nerve: anatomy and clinical 
considerations. Br J Ophthalmol 2003 Jun; 87 (6): 777-81.

25. Geeraerts T, Merceron S, Benhamou D, Vigué B, Duranteau J. Non-invasive assessment of intracranial pressure using ocular sonography in neocritical care patients. Intensive Care Med 2008 Nov; 34(11):2062-7

26. Moretti R, Pizzi B. Optic nerve ultrasound for detection of intracranial hypertension in intracranial hemorrhage patients: confirmation of previous findings in a different patient population. J Neurosurg Anesthesiol 2009 Jan; 21(1):16-20.

\section{Tables}

Table1. Baseline Patient Characteristics.

\begin{tabular}{cc}
\hline \multicolumn{2}{l}{ Patient Characteristics } \\
\hline Total (\%) & $90(100.0)$ \\
\hline Age (yr) ( $\mathbf{( S D})$ & $46( \pm 14.9)$ \\
\hline Sex n (\%) & \\
Female & $38(42.2)$ \\
\hline Male & $52(57.8)$ \\
\hline Diagnostic $\mathbf{n}(\%)$ & \\
\hline TBI & $28(31.1)$ \\
\hline BT & $35(38.9)$ \\
\hline SAH & $27(30.0)$ \\
\hline
\end{tabular}

SD: standard deviation; TBI: Traumatic brain injury; BT: brain tumor; SAH Subarachnoid hemorrhage 
Table 2. Variation of intracranial pressure according to study groups and measurement time.

\begin{tabular}{|c|c|c|c|c|c|c|}
\hline \multirow[t]{2}{*}{ ICP } & \multirow[t]{2}{*}{ Groups } & \multirow[t]{2}{*}{ Mean } & \multirow[t]{2}{*}{$\begin{array}{c}\text { Typical } \\
\text { deviation }\end{array}$} & \multicolumn{2}{|c|}{$\begin{array}{l}\text { 95\% confidence interval for the } \\
\text { average }\end{array}$} & \multirow[b]{2}{*}{$\mathrm{p}$-value } \\
\hline & & & & Lower limit & Upper limit & \\
\hline \multirow{4}{*}{$\begin{array}{c}\text { Basal } \\
(\mathrm{mmHg})\end{array}$} & $\mathrm{M}$ & 40.1 & 9.4 & 36.6 & 43.6 & \multirow[t]{4}{*}{0.96} \\
\hline & $\mathrm{H}$ & 40.6 & 9.2 & 37.2 & 44.0 & \\
\hline & $\mathrm{P}$ & 39.8 & 8.1 & 36.7 & 42.8 & \\
\hline & Total & 40.2 & 8.8 & 38.3 & 42.0 & \\
\hline \multirow{4}{*}{$\begin{array}{c}30 \mathrm{~min} \\
(\mathrm{mmHg})\end{array}$} & M & 23.9 & 5.2 & 22.0 & 25.9 & \multirow[t]{4}{*}{$<0.001$} \\
\hline & $\mathrm{H}$ & 20.9 & 4.3 & 19.3 & 22.5 & \\
\hline & $\mathrm{P}$ & 35.9 & 7.8 & 33.0 & 38.8 & \\
\hline & Total & 26.9 & 8.8 & 25.1 & 28.8 & \\
\hline \multirow{4}{*}{$\begin{array}{c}60 \mathrm{~min} \\
(\mathrm{mmHg})\end{array}$} & $\mathrm{M}$ & 19.5 & 2.7 & 18.5 & 20.5 & \multirow[t]{4}{*}{$<0.001$} \\
\hline & $\mathrm{H}$ & 20.1 & 3.8 & 18.7 & 21.5 & \\
\hline & $\mathrm{P}$ & 35.7 & 7.7 & 32.8 & 38.5 & \\
\hline & Total & 25.1 & 9.1 & 23.2 & 27.0 & \\
\hline \multirow{4}{*}{$\begin{array}{c}90 \mathrm{~min} \\
(\mathrm{mmHg})\end{array}$} & $\mathrm{M}$ & 18.7 & 2.8 & 17.7 & 19.8 & \multirow[t]{4}{*}{$<0.001$} \\
\hline & $\mathrm{H}$ & 18.6 & 3.1 & 17.4 & 19.8 & \\
\hline & $\mathrm{P}$ & 34.5 & 7.2 & 31.9 & 37.2 & \\
\hline & Total & 24.0 & 8.9 & 22.1 & 25.8 & \\
\hline
\end{tabular}

Table 3. ONSD variation according to the different study groups and measurement time. 


\begin{tabular}{|c|c|c|c|c|c|c|}
\hline \multirow[t]{2}{*}{ ONSD } & \multirow[t]{2}{*}{ Group } & \multirow[t]{2}{*}{ Mean } & \multirow[t]{2}{*}{$\begin{array}{c}\text { Typical } \\
\text { deviation }\end{array}$} & \multicolumn{2}{|c|}{$\begin{array}{l}\text { 95\% confidence interval for the } \\
\text { average }\end{array}$} & \multirow[t]{2}{*}{ p-value } \\
\hline & & & & Lower limit & Upper limit & \\
\hline \multirow[t]{4}{*}{ Basal (mm) } & $\bar{M}$ & 7.0 & 0.8 & 6.7 & 7.2 & \multirow[t]{4}{*}{0.12} \\
\hline & $\mathrm{H}$ & 7.1 & 0.8 & 6.8 & 7.4 & \\
\hline & $\mathrm{P}$ & 6.7 & 0.6 & 6.4 & 6.9 & \\
\hline & Total & 6.9 & 0.8 & 6.7 & 7.1 & \\
\hline \multirow{4}{*}{$\begin{array}{l}30 \mathrm{~min} \\
(\mathrm{~mm})\end{array}$} & M & 6.6 & 0.7 & 6.3 & 6.8 & \multirow[t]{4}{*}{$<0.001$} \\
\hline & $\mathrm{H}$ & 6.0 & 0.7 & 5.7 & 6.2 & \\
\hline & $\mathrm{P}$ & 6.6 & 0.6 & 6.4 & 6.8 & \\
\hline & Total & 6.4 & 0.7 & 6.2 & 6.5 & \\
\hline \multirow{4}{*}{$\begin{array}{c}60 \mathrm{~min} \\
(\mathrm{~mm})\end{array}$} & $\mathrm{M}$ & 6.4 & 0.5 & 6.2 & 6.5 & \multirow[t]{4}{*}{0.002} \\
\hline & $\mathrm{H}$ & 5.9 & 0.7 & 5.7 & 6.2 & \\
\hline & $\mathrm{P}$ & 6.5 & 0.7 & 6.2 & 6.7 & \\
\hline & Total & 6.3 & 0.6 & 6.1 & 6.4 & \\
\hline \multirow{4}{*}{$\begin{array}{c}90 \mathrm{~min} \\
(\mathrm{~mm})\end{array}$} & M & 6.3 & 0.5 & 6.1 & 6.4 & \multirow[t]{4}{*}{0.003} \\
\hline & $\mathrm{H}$ & 5.9 & 0.6 & 5.7 & 6.1 & \\
\hline & $\mathrm{P}$ & 6.4 & 0.6 & 6.2 & 6.7 & \\
\hline & Total & 6.2 & 0.6 & 6.1 & 6.3 & \\
\hline
\end{tabular}

Figures 


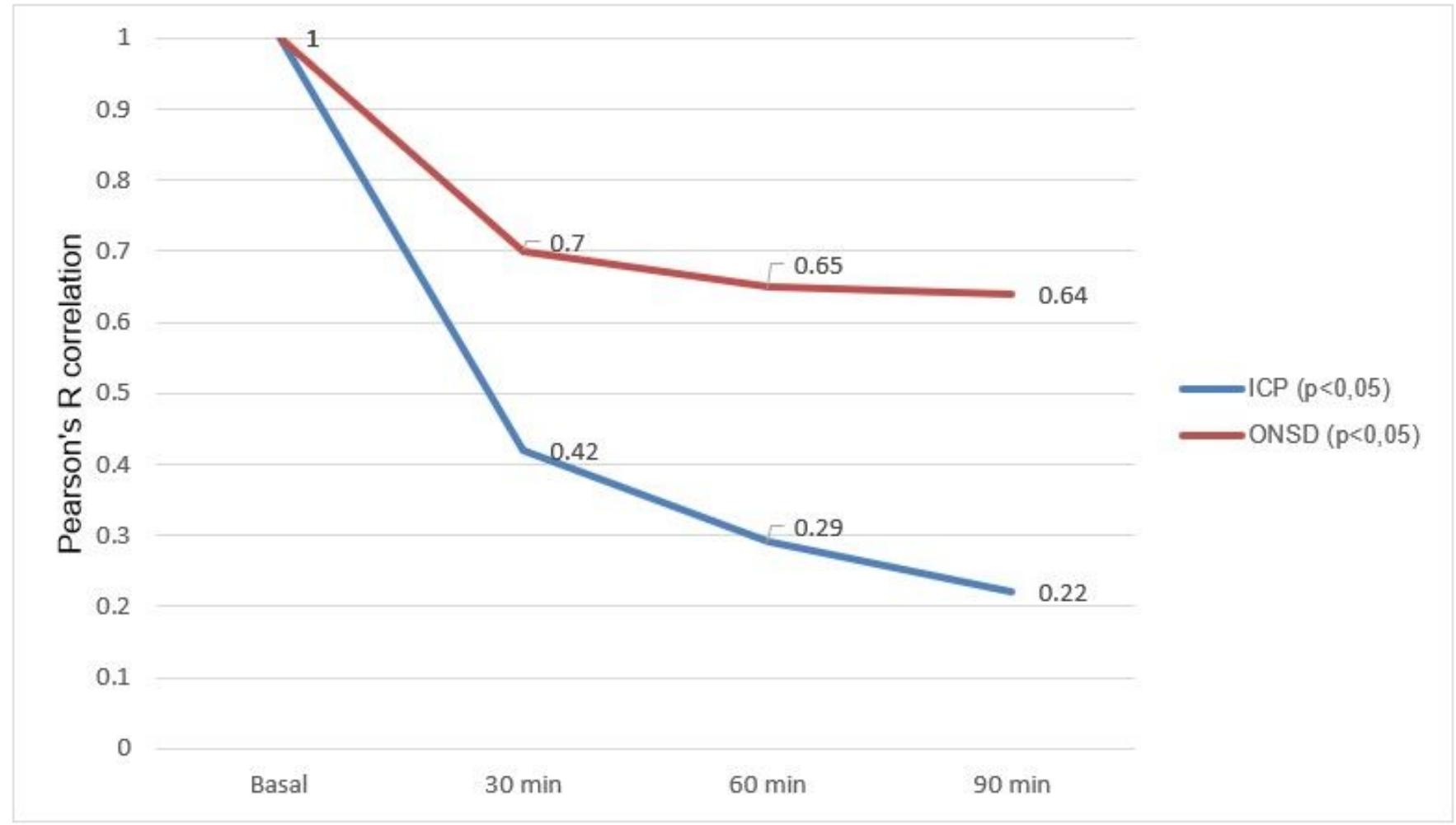

\section{Figure 1}

Pearson's R correlation of intracranial pressure and diameter of optic nerve sheath in patients with intracranial hypertension. 